\title{
MÍDIA E MEMÓRIAS SOCIAIS: Recepção midiática e configurações de memória italiana (RS)
}

\author{
Jiani Adriana Bonin ${ }^{1}$
}

\begin{abstract}
Resumo: O propósito deste artigo é explorar resultados de uma pesquisa que busca investigar o papel das mídias na constituição de memórias étnicas no âmbito da recepção. São recuperadas linhas de fundamentação da pesquisa e explorados dados de uma etapa de pesquisa empírica realizada com imigrantes e descendentes de imigrantes italianos, que permitem visualizar modalidades de ação da mídia e sua relação com outros agentes na constituição da memória destes sujeitos.
\end{abstract}

Palavras-chave: Memória étnica. Recepção. Italianos.

\begin{abstract}
The aim of this article is to explore results of a research that investigates, under the reception field, the role of media on the formation of ethnic memory. The work recovers theoretical lines that guide the investigation and explores data from one stage of empirical research, made with Italian immigrants and descendents of Italian immigrants, that allows us to visualize modes of action of the media and its relation with other agents on the formation of the memory of these people.
\end{abstract}

Key-words: Ethnic memory. Reception. Italians.

\section{Os contornos de uma problemática: a midiatização da memória italiana na recepção}

O relevo que a questão da memória vem adquirindo nas sociedades atuais tem instigado o trabalho de reflexão de autores e pesquisadores de vários campos científicos, situados em contextos diferenciados ${ }^{2}$. Atenta-se para a constituição de uma cultura da memória, que se manifesta em distintos contextos sociais. A despeito de particularidades dos contextos, assinala-se o caráter global que adquirem certos fenômenos e particularmente o que me ocupa neste texto - a significativa atuação da Indústria Cultural nestes processos ${ }^{3}$. Assim, o que se revela é que, no contexto da midiatização da sociedade,

\footnotetext{
${ }^{1}$ Doutora em Ciências da Comunicação pela Escola de Comunicação e Artes/USP; Professora e pesquisadora do Programa de Pós-Graduação em Ciências da Comunicação da UNISINOS. Email: jianiab@unisinos.br ${ }^{2}$ Entre eles Rossi (2003), Ricoeur (2003), Todorov (2000,2002), Le Goff (2003), Martín Barbero (2001), Sarlo (2007), Huyssen (2000, 2005), Candau (2002), Montesperelli (2004) e Berger (2005).

${ }^{3}$ Fenômenos recentes como o Holocausto têm catalizado discussões em torno da construção da memória deste acontecimento, na medida em que se torna objeto de investimento de distintos agentes, inclusive da mídia (Ver, por exemplo, Huyssen, 2000). Outros fatos que marcaram a história política de países da América Latina, como as ditaduras, fazem emergir a questão da memória com força na cena pública, ao se tornar objeto de reivindicação e disputas políticas e sociais. Isto é particularmente evidente no caso da Argentina. Ver neste sentido Jelin (2003).
} 
as mídias passam a atuar também na constituição das memórias sociais, realidade que nos desafia a pensar, via investigação, as particularidades desta ação configuradora.

Esta questão ganha uma particular concretude quando pensada em relação ao papel da mídia em relação a memórias constitutivas de identidades culturais, como as étnicas. No cenário sociocultural do Rio Grande do Sul, marcado por migrações históricas e contemporâneas constitutivas de identidades que persistem, é possível observar uma oferta significativa, em mídias locais e regionais, de sentidos sobre estes grupos. Entre eles destacam-se os italianos, com forte presença enquanto uma das correntes migratórias mais expressivas no processo de colonização do estado. Mas a presença midiática deste grupo não se dá somente nas mídias locais: produções como as telenovelas Terra Nostra e Esperança, além de outras, demonstram que tal presença também se pode ver no âmbito da mídia nacional; canais como a RAI ofertam produtos de natureza global que se inserem no âmbito local/regional ${ }^{4}{ }^{[4]}$

As transformações na conformação coletiva/individual da memória étnica deste grupo vêm sendo investigadas no projeto Mídia e memórias: palimpsestos midiatizados de memória étnica na recepção ${ }^{5}$, que coordeno, cujo objetivo geral é investigar os palimpsestos de memória étnica de descendentes de imigrantes italianos e de imigrantes argentinos, buscando compreender como as mídias se instituem como lugares de configuração destas memórias e como se relacionam com outros âmbitos neste processo. Entendemos que, para investigar esta ação configuradora da mídia, precisamos considerar suas relações com outros âmbitos de mediação da memória, assim como atentar para as lutas simbólicas que se expressam no ordenamento da memória e do esquecimento na recepção.

Dois eixos de problematização, já desenvolvidos em outros artigos (BONIN, 2006, 2008), são nucleares para pensar esta problemática: o primeiro, relativo à noção de memória coletiva e o segundo, referente à questão da ação das mídias nos processos de constituição das memórias.

A noção de memória coletiva tem, na obra de Maurice Halbwachs, um marco importante de desenvolvimento, no sentido de pensar a dimensão propriamente social da

\footnotetext{
${ }^{4}$ Ver a este respeito os trabalhos de Bonin (2007), Cogo (2006) e Oliveira (2007).

${ }^{5} \mathrm{O}$ projeto, sob minha coordenação, conta com financiamento da UNISINOS (estrutura e bolsa de iniciação científica) e da FAPERGS (bolsa de iniciação científica). Trabalham atualmente no projeto os bolsistas Bruno S. Alencastro (BIC-FAPERGS) e Stefanie Telles (UNIBIC-UNISINOS). Em relação a esta pesquisa, já foi publicado um artigo sobre a problemática teórico-metodológica que a fundamenta (BONIN, 2006). Um texto com resultados preliminares de investigação, onde formam discutidos dados de duas entrevistas realizadas com sujeitos que se identificam como italianos foi apresentado no Congresso da INTERCOM em 2008 (BONIN, 2008).
} 
memória. Para ele, a memória individual se assenta e se organiza com base em quadros sociais; carrega consigo a dimensão social dada pela linguagem, pela inserção do indivíduo num contexto social e em relações de pertencimento; ampara-se e constitui-se nas relações que o indivíduo mantém com os demais membros de seus grupos de pertença. A memória coletiva, nesta perspectiva, é pensada como a seleção, a interpretação e a transmissão de certas representações do passado a partir do ponto de vista de um grupo social determinado (Halbwachs 1990). O pensamento deste autor acentua o caráter seletivo da memória social, sua força quase institucional, seu papel de reforço na coesão social pela adesão afetiva ao(s) grupo(s) de pertencimento.

O conceito de memória coletiva conserva fecundidade para pensar formas de consciência do passado de alguma maneira compartilhadas pelos grupos étnicos. É possível admitir que estes grupos partilham certas percepções fundamentais, marcos sociais de memória, como propõe Candau (2002). Mas, no interior destas configurações, pensamos que cada indivíduo pode impor seu próprio estilo, estreitamente dependente de sua história, dos contextos vivenciados, entre outros fatores. Entretanto, desde esta perspectiva, não é possível problematizar os conflitos, as relações de poder e, principalmente, a ação das mídias na constituição das memórias.

Numa outra linha, a partir de uma perspectiva construtivista, Pollack (1989) contribui para a problemática, ao deslocar as preocupações para os processos, sempre conflitivos, as disputas e os atores que intervêm na configuração das memórias. Nesta perspectiva, os marcos sociais de memória são o resultado, nunca adquirido definitivamente, de conflitos e compromissos entre distintas memórias. Diferentes grupos e agentes competem pela hegemonia sobre os discursos plausíveis e relevantes sobre a memória dentro da sociedade e em seu conjunto, o que permite pensar a problemática do poder da configuração das memórias investigadas.

Seguindo este autor, é importante considerar a função da memória como “operação coletiva de seleção/constituição dos acontecimentos e interpretações do passado que se quer salvaguardar", que "se integra em tentativas mais ou menos conscientes de definir e de reforçar sentimentos de pertencimento e fronteiras sociais entre coletividades" (Pollack, 1989, p.9). O autor propõe a noção de memória enquadrada para pensar a construção de memórias sociais por agentes diversos, atentando para o trabalho de fabricação (que inclui, por exemplo, a escolha das testemunhas autorizadas a falar) e de controle sobre a memória que aí se realizam. Isto nos leva à segunda linha de problematização, a questão da ação das mídias nestas memórias étnicas. 
Os conceitos de midiatização e de cultura midiática nos ajudam a pensar as alterações substantivas que vêm se dando em termos do redesenho dos modos como a sociedade se estrutura, produz significados, se comunica, se reproduz e se transforma no decorrer do processo de expansão e inscrição das mídias nos diversos âmbitos sociais. Nesta via, pode-se pensar que o processo de midiatização também vem se dando no âmbito das memórias sociais. Podemos propor, seguindo Mata (1999), que a mídia vem se instituindo como matriz, racionalidade produtora e organizadora de sentidos relativos às memórias sociais e, mais especificamente, das memórias étnicas, que nos interessam nesta pesquisa.

Compartilhamos com a proposição de Henn (2006, p.179) de que as mídias passam a constituir um "lugar privilegiado para os agenciamentos envolvendo a memória coletiva e, sobretudo, o enquadramento da memória.” Esta noção de enquadramento também é recuperada por este autor desde a perspectiva da hipótese da agenda setting, em sua proposta de que os produtos noticiosos não apenas definem uma agenda a ser pensada, mas também as formas como pensar estas questões a partir daquilo que incluem e excluem, das hierarquizações e dos enfoques propostos, segundo suas lógicas próprias, definindo, portanto, o que da realidade é relevante. Nesta linha, é possível pensar nas mídias como produtoras de enquadramentos que podem incidir nas configurações das memórias dos grupos, bem como na instauração de esquecimentos.

Por outra parte, é importante levar em conta as modificações atuais da memória em sua relação com a transformação da estrutura da temporalidade social e da experiência do tempo, provocadas pela intersecção complexa entre mudança tecnológica, mídia e novos padrões de consumo, trabalho e mobilidade global, assim como em relação à planificada obsolescência dos objetos cotidianos pelo mercado - da qual faz parte a acelerada sincronicidade produzida pelos meios. Estas, aliadas ao descentramento das ancoragens identitárias, parecem levar à vitória do presente e instauram o risco da amnésia. Entretanto, paradoxalmente, parecem gerar também um desejo de passado, que expressa a necessidade de ancoragem temporal que sofrem as sociedades (e os grupos) cuja temporalidade é atingida pela revolução tecnológica informacional, manifestando a transformação profunda por que passa a estrutura de temporalidade que legamos da modernidade. Transformação que desestabiliza o lugar do passado como lastro e faz da novidade a fonte de legitimidade cultural (Martín Barbero 2001; Huyssen 2005).

Numa discussão que se articula a esta, Martín Barbero (2006) fornece outras pistas para pensar a ação das mídias sobre as memórias, ao refletir sobre a fragmentação dos 
relatos que se instaura via o que ele chama de ecossistema discursivo dos meios, com suas linguagens e escrituras. As mídias instauram novos modos de narrar, condicionados por seus dispositivos, gêneros e linguagens, potenciando a coexistência de códigos e relatos diversos, que incidem sobre a experiência de conformação dos relatos de memória. A experiência multifacetada da recepção hoje, configurada por múltiplos palimpsestos midiáticos de memória, assim como as especificidades da gramática narrativa dos relatos midiáticos, institui uma experiência de fragmentação/proliferação dos relatos.

$\mathrm{Na}$ esteira destas proposições, pensamos que a memória étnica deve estar sofrendo transformações e que a mídia pode estar atuando como agente importante de configuração e transformação dos lugares ou enquadramentos de memória - produção marcada por suas matrizes, seus gêneros, suas modalidades narrativas e sua racionalidade de produção de sentido - assim como de esquecimentos. Entretanto, em sua configuração, é possível pensar que se articulam marcas coletivas/individuais fabricadas em outros lugares: na experiência cultural e vivencial dos sujeitos, constituídas desde seu lugar social, dos contextos de seu mundo, da vida e das redes de relações que aí se estabelecem - âmbitos que podem ser pensados como mediações (Martín Barbero, 1997).

É atentando para o jogo conflitivo entre estes outros lugares e a ação da mídia que se abrem possibilidades produtivas para entender a conformação destes palimpsestos midiatizados de memória, dos conflitos que os marcam e do sentido particular que adquirem. A noção de palimpsesto é originalmente utilizada por Martín Barbero (1997) para pensar a trama de textos e de matrizes culturais presentes nos gêneros, e por Martín Barbero e Germán Rey (2001, p.63) para pensar em textos nos quais “um passado apagado emerge tenazmente, embora imprecisamente, nas entrelinhas escritas pelo presente". Apropriamo-nos dela para pensar a trama de referentes, midiáticos e não midiáticos, que se inscrevem na memória étnica dos sujeitos dos grupos investigados.

Empiricamente nos interessa, principalmente, analisar estas questões desde o âmbito da recepção. Assim, os relatos de memória étnica midiatizada dos sujeitos se instituem como dados empíricos fundamentais. E são relatos advindos de uma primeira etapa desta pesquisa que exploramos na seqüência, com vistas a apontar algumas constatações e pistas relacionadas à problemática investigada.

Esta etapa da investigação foi realizada com uma amostra de 16 italianos, de composição diversa em relação à escolaridade, profissão, sexo e trajetória de vida dimensões que consideramos importantes para pensar diversidades de configuração de memórias midiatizadas. A coleta de dados, nesta fase, foi realizada a partir de uma 
entrevista semi-estruturada, orientada por um roteiro contendo blocos de questões relativos à memória midiática, memória comunicacional, definição identitária, perfil sócioeconômico e trajetórias de migração ${ }^{6}$.

\section{Explorando as memórias midiatizadas dos italianos entrevistados: algumas constatações}

Uma primeira constatação que podemos assinalar, quando consideramos os relatos de memória dos entrevistados coletados nesta etapa da pesquisa, é que a mídia está implicada, em maior ou menor grau, na produção de marcas de memórias relacionadas à italianidade.

A presença destas marcas midiáticas de memória varia em intensidade nos relatos, o que parece estar associado a vários fatores, figurando, entre eles, a particularidade da trajetória de consumo dos entrevistados e sua relação com as distintas mídias. E aqui uma distinção que se apresenta recorrente é a presença menos expressiva de referências de memória midiática entre os idosos, que contrasta com uma expressiva evocação de memórias constituídas nas trajetórias de vida destes sujeitos e nas relações comunicacionais do cotidiano. Nesta constatação, se expressa como mediação relevante a própria história de aparecimento e consolidação das mídias, na medida em que gerou distintas trajetórias de consumo midiático. No caso dos idosos, por exemplo, o rádio foi pioneiramente a mídia consumida; já a televisão se insere no cotidiano desses sujeitos na juventude ou na fase adulta, sendo que as modalidades de consumo deste meio são, em geral, menos intensas que em relação a outros entrevistados. O consumo de mídia impressa, de modo geral, é pouco expressivo entre os idosos entrevistados (o que se relaciona, também, com a escolaridade limitada destes sujeitos, entre outros fatores) e a Internet não figura no consumo.

Se observarmos estas marcas de memória midiáticas sob o aspecto de distinção das recordações configuradas nos relatos, uma característica marcante é que estas lembranças, em geral, não evocam singularidades episódicas, acontecimentos particulares, mas se constituem como marcas de tipicidades, esquemas ou matrizes. Neste sentido, constatamos que um dos modos mnemônicos que Ricoeur (2003) trabalha, ao propor uma tipologia que

\footnotetext{
${ }^{6}$ A primeira etapa de coleta de dados relativos a esta pesquisa foi realizada em 2007. Uma segunda etapa de investigação empírica, em execução, está sendo realizada com uma amostra de seis sujeitos participantes desta primeira etapa, escolhidos conforme distinções que se mostraram relevantes para entender a configuração das memórias midiatizadas nestes grupos. A coleta de dados, nesta segunda etapa, está sendo realizada através de relatos de vida étnica comunicacional/midiática, observação e fotografia.
} 
busca pensar as recordações em termos de diferenciação das marcas de memória, se expressa como preponderante nos modos como se manifestam as marcas de memória midiática, diferentemente de outras formas de memória, onde se observa, conforme este autor, um leque de possibilidades entre o que ele chama de memória episódica, singular, e memória de generalidades ${ }^{7}$. Esta constatação parece apontar para a rememoração de temas agendados e de modalidades de enquadramentos destes temas recorrentes nas mídias. Isto possibilita pensar que a mídia se expressa aqui como instância configuradora de matrizes e esquemas presentes como marcas nas memórias dos entrevistados, na linha proposta por Mata (2002). Mas a força destes esquemas não parece explicar-se somente pela ação recorrente da mídia; encontramos, também, relações de similaridade e de complementaridade entre as marcas midiáticas e outras relacionadas a vivências do passado e constituídas nas relações comunicacionais do cotidiano.

Exemplifiquemos estas constatações com dados advindos da entrevista de Maria do Rosário (51 anos), filha de pai italiano e de mãe brasileira. Esta entrevistada nasceu no Uruguai e veio para Bento Gonçalves (RS, Brasil) com 19 anos, onde se casou com um descendente de italianos. Atualmente mora em Novo Hamburgo (RS, Brasil). As marcas de memória midiática mais significativas narradas por ela remetem a recordações relativas a documentários assistidos na RBS TV (que ela aponta como marcantes). Nelas se pode vislumbrar certo modo de enquadramento constituindo os sentidos destas marcas de memória calcadas nas dificuldades, no espírito de empreendimento, em valores como força de vontade, perseverança e na exaltação das conquistas dos imigrantes:

Eu vi nesses documentários (...) mostrou desde que eles chegaram, todas as dificuldades que eles passaram quando eles chegaram aqui, até conseguir construir uma estrutura que facilitasse um pouco mais a vida deles. Eles chegaram aqui sem nada e tiveram que plantar pra conseguir comer, caçar o que aparecesse no meio do mato para conseguir alimentar a família e aí mostraram o que eles conseguiram hoje, o que significa pro Estado hoje o fato deles terem vindo. Porque se tu imaginar que eles chegaram aqui com os filhos e uma trouxa de roupa e mais nada, e deram um pedaço de terra numa encosta e hoje tu vês cidades como Bento, Caxias, Farroupilha e Garibaldi! Bento foi considerada um ano atrás a segunda melhor cidade pra viver, saúde, saneamento, tudo mais. Como

\footnotetext{
${ }^{7}$ Ricoeur (2003) em sua obra La memória, la história, el olvido esboça uma tipologia de modos mnemônicos múltiplos que a descrição encontra, ao trabalhar uma fenomenologia da recordação. Argumenta que, entre outras características, as recordações apresentam graus variáveis de distinção: num continuum se revelam desde as singularidades episódicas, relativas à recordações de circunstâncias particulares até as recordações relativas a estados de coisas, que se referem a noções e generalidades abstratas. Entre estes extremos situamse as recordações que se referem não a uma singularidade, mas à semelhança que se expressa em experiências que se repetem e que aparecem sob a forma de marcas de memória que retém as semelhanças típicas.
} 
aquela trajetória conseguiu dar um resultado como esse! É uma questão de admiração por saber que pessoas... chega até a emocionar, pessoas que chegaram aqui com fome, sem dinheiro, que foram distribuídos que nem animais praticamente "Tu fica aqui, tu fica ali". (...) Mas eles com a perseverança, a vontade, a garra, conseguiram fazer uma cidade como Bento, como Caxias, que são pólos na economia do Estado, muitas até do Brasil. Eu acho que isso é uma coisa que a gente tem que tirar o chapéu e bater palmas, porque eles conseguiram (Maria do Rosário).

Este enquadramento, pelo que pude observar em pesquisa anterior, está presente na cobertura regional que a RBS realiza deste grupo étnico (Bonin, 2007). Mas se pode vislumbrar que foi constituído também no contato com outras mídias locais e regionais consumidas pela entrevistada, assim como nas relações comunicacionais vividas no contexto de Bento Gonçalves (destacando-se aqui o papel da sogra no sentido de contar a ela a memória dos antepassados) entre outros possíveis. Neste sentido, é possível pensar que a mídia televisiva regional, no caso a RBS, figura como agente importante na instituição desta matriz de enquadramento da memória étnica, mas também se articula com a seleção do passado trabalhada por outros agentes deste contexto local/regional. Veja-se, por exemplo, o relato de João, 44 anos, educador, nascido em Paraí (RS) e que vive atualmente em Novo Hamburgo (RS).

Que eu lembro que foram os primeiros anos, anos de muitas dificuldades. Por exemplo, os primeiro imigrantes chegaram aqui de navio, sem conhecer absolutamente nada, a locomoção era uma tarefa muito difícil. Me lembro que a minha família, quando vieram, parece que eram dois irmãos, se estabeleceram em Alfredo Chaves, próximo a Antônio Prado, mais próximo a Veranópolis, se instalaram ali. Eles chegaram a determinado ponto que eles, um deles parece que era casado, deixou a esposa e eles saíram com facões abrindo picadas no meio do mato para chegar a um determinado lugar. Neste lugar construíam uma casinha bem simples e começavam um plantio das lavouras para subsistência. Então, quando eles tinham essa cultura criada, eles voltavam e buscavam a família. Tinha um risco muito grande, não tinha tratamento de saúde, tanto é que a estimativa de vida era bem baixa. Eles tinham muito medo dos animais ferozes, eu me lembro que a minha mãe contava que eles ficavam dormindo e ao redor da casa ficavam tigres fazendo barulho. Mas esses eram obstáculos que aos poucos eles iam superando.(João, 44 anos, educador).

Neste caso, revela-se a ação da mídia no sentido de reforçar e/ou instituir estes enquadramentos de memória. Enquadramentos estes que, neste caso, mascaram contradições sociais e, ao mesmo tempo, colaboram para a persistência de uma visão etnocêntrica dos italianos como grupo que tem como uma das marcas distintivas a 
superioridade do trabalho e do empreendimento - marca esta que estaria na base do progresso econômico deste grupo e das cidades que fundaram.

Como argumentado anteriormente, analisando os relatos dos entrevistados se pode ver que as marcas midiáticas de memória têm, em muitos casos, relação significativa também com marcas advindas da trajetória de vida dos sujeitos e das relações comunicacionais estabelecidas nesta trajetória. E esta constatação nos encaminha, também, para outra modalidade de ação da mídia: é possível ver que certos referentes de memória midiática agem como pontos de apoio para a rememoração de marcas relacionadas a vivências dos entrevistados ou mediadas por relatos de outros agentes do cotidiano. Esta ação de determinados objetos, incluindo midiáticos, como apoio à rememoração é discutida por Ricoeur (2003) ${ }^{8} .^{7]}$ Veja-se por exemplo, estes fragmentos do relado de um agricultor aposentado de 65 anos, nascido em Linha Feliz (RS) e hoje residente em Igrejinha (RS), ao recordar as músicas que escutava e ainda escuta no programa Momento Italiano, veiculado aos sábados na rádio comunitária de Igrejinha e ao lembrar-se da telenovela Terra Nostra:

Muitas eu já escutava desde o tempo de guri e muitas já são mais de agora, a Massolini Di Fiori, a Mérica, são umas músicas muito antigas, que a gente desde pequeno sabia destas músicas, que o meu pai cantava. Eu não tenho voz pra cantar, mas o meu pai era um professor pra cantar. Ele, de noite na colônia, não tinha rádio, não tinha nada na época, então a gente ia ali tomar um chimarrão e depois ele começava a cantar. Ele tinha uma voz pra cantar que era coisa mais linda. (Dalmo, 65 anos, agricultor aposentado).

Sim várias coisas assim eu até que guardei [da novela Terra Nostra], como o sistema do cáspita, que eles falavam assim, da família italiana com rigor, levar a família sempre na dureza. Eu lembro que eles faziam assim. Eu me lembro disso, que eles eram duros, rigorosos. Assim eu lembro, eles faziam essas partes, mas eu nem sei explicar como era (...) com a família, os filhos, as filhas de dar aquela tarefa rigorosa, eles tem que ser assim, "Não quero que tu namore aquele, não quero que você faça isso.” Era coisa dura. (...) Antigamente muita gente era por ali mesmo, era duro, naquele sistema rígido. Os últimos anos isso está mudando, mas quando eu fui criado, o sistema do meu pai e da minha mãe, era rígido, do meu sogro. Quando chegava alguma visita na casa do meu pai, quando chovia, os vizinhos iam lá tomar um chimarrão, porque não dava pra trabalhar na roça, o meu pai só dava uma olhada e nós sabíamos. Não

${ }^{8}$ Em sua discussão sobre os modos mnemônicos que se expressam nas recordações, Ricoeur (2003) recupera o trabalho de Casey (1987), intitulado Remembering, que também discute os modos como a recordação se configura e onde identifica o que denomina de reminding, que aludiria a indicadores encaminhados a proteger contra o esquecimento; entre eles indica fotos, cartões postais, notas, que funcionariam como pontos de apoio para a rememoração. 
precisava dizer nada, era só dar uma olhada que nós pegávamos à porta, ia pro galpão, ia descascar milho. Era severo, jeito duro. (Dalmo, 65 anos, agricultor aposentado).

Atentando especificamente para o trabalho de rememoração, é possível pensar que certos referentes de memória midiática agiriam como estímulo neste processo. Se tomamos como modelo para entender este trabalho de rememoração a proposta bergsoniana, podemos pensar que estes referentes midiáticos atuam como esquemas suscitadores da lembrança, quando esta deve, de recordação pura, transformar-se em imagem que permite o seu reconhecimento no processo rememorativo. A mediação deste processo, conforme Bergson (1999), é realizada por esquemas que guiam o trabalho de lembrança e seria este um papel que também estariam realizando os referentes midiáticos.

Em nível coletivo, certos relatos também apontam para o uso de referentes das mídias em processos de rememoração do passado com apoio de outros, que se ajudam mutuamente na reconstrução de memórias, tal como constatou Strohschoen (2003) em sua pesquisa relativa à recepção de Terra Nostra por italianos.

Neste sentido podemos pensar que as mídias operam também como estímulos para a rememoração de certos acontecimentos relativos à italianidade, direcionando, neste processo, o que lembrar do fundo memorial que os sujeitos detêm (e conseqüentemente, também, atuando sobre o que esquecer). Este parece ser o caso da cena fundante de vinda dos italianos, reconstruída na telenovela Terra Nostra, lembrada por um número expressivo de entrevistados, referindo-se também a relatos ouvidos de avós ou bisavós, ou de marcas de memória que remetem a costumes culturais como a culinária, a dança, etc., bastante presentes na cobertura da mídia regional (ver neste sentido Bonin, 2007).

Curiosamente, neste processo, a ação de estímulo à rememoração também pode suscitar recordações dissonantes em relação aos enquadramentos ofertados pelas mídias, momento em que as marcas de memória relativas a vivências ou relatos de outros agentes do cotidiano assumem força enquanto enquadramento legítimo da memória. Um caso extremo, dentre os entrevistados, é representado por pai e filho nascidos na Itália que migraram para o Brasil, vivendo hoje em Novo Hamburgo. Ao relatarem suas lembranças midiáticas relacionadas aos italianos, questionam agendamentos e enquadramentos de memória italiana na mídia regional. O relato do filho ilustra estes questionamentos:

O que eu me lembro de cultura, de tradição é bem diferente do que a gente vê aqui da cultura italiana, que é tudo polenta, galeto. (...) talvez as pessoas que trouxeram a tradição italiana pra cá, são do final do Século 
XVIII, então, se passou um século, então é uma diferença. A música que a gente escuta aqui dos italianos é uma música bem mais antiga. (...) Os descendentes dos imigrantes italianos da época, eram de outra situação, outra realidade, antes da Guerra ou no próprio período de Guerra. (Giovanni, 26 anos, empresário).

Mas também outros casos apontam para dissonâncias entre as marcas de memória midiática e outros referentes de memória dos entrevistados. Nestes casos, se pode pensar na função mediadora das marcas de memória vividas ou constituídas nas relações cotidianas, funcionando como operadores de apropriação (Certeau, 1996). Este fragmento do relato de Fernando, estudante de comunicação nascido em Guaporé e que hoje vive em Carlos Barbosa, na serra gaúcha, é ilustrativo:

Eu lembro do Quatrilho, apesar de ser um filme bastante assistido, foi bastante contestado. Tem erros de conduta dos italianos. Falava-se bastante lá em Carlos Barbosa daquela cena de sexo, que não se fazia assim naquela época, meu Deus do céu! (...) eu me lembro que foi muito contestado, esta cena em especial, eu lembro que tinha um amigo do pai lá em casa e eu lembro que estavam conversando sobre o filme, que naquela época não se colocava uma mulher em cima da mesa.(Fernando, 22 anos, universitário).

Persistem também certas marcas de memória que não parecem ter conexão com aquilo que a mídia pauta. É o caso da memória da campanha da nacionalização que se mantém como marca de memória subterrânea (Pollack, 1989) nos relatos de alguns dos idosos entrevistados que viveram este período, em função da proibição da língua, como se pode ver no depoimento de Celeste, nascida em Guaporé e hoje moradora de Novo Hamburgo:

Sim, em casa [falavam o italiano], mas depois houve uma guerra que proibia falar em italiano. Coitado daquele povo, por que eles não sabiam falar em português e os poloneses menos ainda. Foi uma confusão muito séria. Tinha pessoas de idade, eu lembro pelo meu pai, imagina, eu tenho 81. Então eles não sabiam falar em português e era proibido falar italiano, eles sabiam falar italiano um pouco mais, porque esta gente convivia mais com a língua italiana, esta gente de outra nacionalidade eu não sei de onde eles vieram. Acho que eles vieram da Polônia (...) mas eu já era aluna. Eu entendia bem claro o português. Já desde pequena a gente procurava falar em português em casa mesmo porque, na época, vinham viajantes para o nosso comércio e eles falavam português. Para os mais velhos era muito mais difícil. Pra nós jovens, nós conseguimos nos defender, mas para os mais velhos foi muito difícil. (Celeste, 81 anos, comerciante aposentada). 
É interessante notar como estas marcas não encontram um sentido mais amplo, ou seja, não alcançam situar-se em relação aos acontecimentos históricos que determinaram estas vivências.

A persistência de marcas como estas, assim como aquelas relativas em particular a vivencias do cotidiano, sugere que as mídias não respondem pela totalidade das marcas de memória italiana presentes nas narrativas dos entrevistados. No caso destas modalidades de memória, expressam-se particularmente marcas de vivências relacionadas ao trabalho, aos modos de vida, à culinária, à prática da língua, particularmente entre os entrevistados de mais idade. Neste sentido, os acontecimentos biográficos são os que mais se destacam nos relatos de memória, apontando para a questão de que parece estar se restringindo a extensão temporal da memória étnica (em termos de constituição de uma memória intergeracional). O que certamente tem relação com as transformações, discutidas por Martín Barbero (2001), da estrutura da temporalidade social e da experiência do tempo, provocadas pelas mudanças tecnológicas, pela ação das mídias, por novos padrões de consumo e a planificada obsolescência dos objetos cotidianos pelo mercado - da qual faz parte a acelerada sincronicidade produzida pelos meios.

Pode-se pensar, por outro lado, que a mídia opera no sentido de reconectar, de certa maneira, esta memória de natureza individual (biográfica) e familiar, íntima, com uma memória de natureza mais extensiva. Isto se revela com particular força em termos de uma memória coletiva local e regional (de imigrantes italianos nos estados da Serra Gaúcha, em muitos casos), mas também em termos nacionais e mesmo globais.

Em relação à memória midiática de caráter marcadamente nacional, destacam-se as telenovelas Terra Nostra e Esperança, cujas referências permitem a alguns entrevistados pensar em semelhanças e distinções em termos dos contextos vividos por migrantes do sudeste e do sul, como se pode ver no relato de Maria do Rosário:

Principalmente o italiano que veio na época pra região de São Paulo, ele é como se fosse muitas vezes um escravo que veio substituir o negro na época da abolição. (...) O italiano que veio na época substituir aquele pessoal que trabalhava nas plantações de café, ele também é mostrado até hoje como uma pessoa sem valor e muitas vezes não é dado o valor que ele teve. Eu acho que deveria ter um documentário, alguma coisa que mostrasse o que ele conseguiu fazer e o que hoje significa ele ter vindo pra cá, pro Brasil, pro Estado, a importância do que ele deixou hoje, do que ele tem feito hoje e como ele chegou aqui. Vê que ele não foi um substituto ou uma pessoa sem valor que veio pra plantar café, mas foi uma pessoa que teve muita coragem pra lutar, pra enfrentar os obstáculos que ele encontrou que foram muitos e conseguir vencer (Maria do Rosário, 51 anos, dona de casa). 
Em relação a marcas de caráter global, destacam-se aquelas relativas ao consumo de programações de canais de TV como a RAI, de rádios italianas consumidas pela internet (caso de jovens), de filmes e de música italianos.

\section{Considerações finais}

As explorações e análises dos dados recolhidos realizadas até agora evidenciam, portanto, a ação configuradora das mídias na constituição das memórias relativas à italianidade dos sujeitos entrevistados. Esta ação se materializa em diferentes formas e produz resultados diferenciados de acordo com experiências, relações cotidianas e consumos midiáticos dos sujeitos ao longo da sua trajetória. Entretanto, verifica-se que as mídias são parte destas trajetórias e, particularmente as regionais, vêm atuando no sentido de construir e reforçar certos enquadramentos desta memória local/regional, presentes também em outros âmbitos de configuração destas memórias. Neste sentido, elas atuam vinculando memórias biográficas e familiares a esta memória midiática local/regional. Os dados apontam, entre outras coisas, para uma tendência de reforço de uma matriz de enquadramento que exalta as dificuldades vividas pelos imigrantes e sua superação pelo trabalho, esforço e empreendimento, que marcariam uma distinção cultural deste grupo e estariam na base do seu progresso econômico e das cidades que fundaram.

As mídias também colaboram para vincular marcas de memórias locais/regionais a construções de memórias nacionais e mesmo globais, produzindo palimpsestos de memórias onde se vinculam marcas de âmbitos diversos.

\section{Referências bibliográficas}

BERGER, C. Proliferação da memória: a questão do reavivamento do passado na imprensa. In: BRAGANÇA, A.; MOREIRA, S. V. (orgs.) Comunicação, acontecimento e memória. São Paulo: Intercom, 2005, p.60-69.

BERGSON, H. Matéria e memória. Ensaios sobre a relação do corpo com o espírito. São Paulo: Martins Fontes, 1999.

BONIN, J. Mídia e memórias: delineamentos para investigar palimpsestos midiatizados de memória étnica na recepção. Revista Fronteiras - Estudos Midiáticos, n.2, vol. 3, São Leopoldo, 2006, p.133-143.

- Mídia televisiva regional e identidade étnica: a RBS e as configurações da identidade italiana na recepção. Revista Fronteiras - Estudos Midiáticos, n.2, vol. 9, São Leopoldo, 2007, p. 91-103. 
Mídia e memórias: explorações sobre a configuração dos palimpsestos de memória étnica italiana na recepção. In: XXXI Congresso Brasileiro de Ciências da Comunicação. Anais do XXXI Congresso Brasileiro de Ciências da Comunicação. São Paulo: INTERCOM, 2008. v. 1. p. 1-15.

CANDAU, J. Antropologia de la memória. 1. ed. Buenos Aires: Nueva Visión, 2002.

CERTEAU, M. A invenção do cotidiano: artes de fazer. 2. ed. Petrópolis: Vozes, 1996.

COGO, D. Mídia, interculturalidade e migrações contemporâneas. Rio de Janeiro: Epapers; Brasília, DF: CSEM, 2006.

HALBWACHS, M. A memória coletiva. São Paulo: Vértice, 1990.

HENN, R. Direito à memória na semiosfera midiatizada. Revista Fronteiras - Estudos midiáticos, n. 3, v.8, São Leopoldo, 2006, p.177-184.

HUYSSEN, A. Seduzidos pela memória: arquitetura, monumentos, mídia. Rio de Janeiro: Aeroplano, 2000.

. Resistência à memória: usos e abusos do esquecimento público. In: BRAGANÇA, A.; MOREIRA, S. V. (orgs.) Comunicação, acontecimento e memória. São Paulo: Intercom, 2005. p.26-36.

JELIN, E. Los derechos humanos y la memoria de la violencia política y la represión: la construcción de un campo nuevo en las ciencias sociales. Buenos Aires: Instituto de Desarrollo Económico y social, 2003. 27 p.

LE GOFF, J. História e memória. Campinas: Unicamp, 2003.

MARTÍN-BARBERO, J. Dos meios às mediações: comunicação, cultura e hegemonia. Rio de Janeiro: UFRJ, 1997.

. El futuro que habita la memoria. PCLA Revista científica digital, n. 3, São Paulo, 2001, p.1-18. Disponível em: <www2.metodista.br/unesco/PCLA/revista7/artigo\%2071.htm^^>. Acesso em: 10 de abril de 2009.

. Tecnicidades, identidades, alteridades: Mudanças e opacidades da comunicação no novo século. In MORAES, D. (org.) Sociedade midiatizada. Rio de Janeiro: Mauad, 2006. p.51-79.

MARTÍN-BARBERO, J. REY, G. Os exercícios do ver: hegemonia audiovisual e ficção televisiva. São Paulo: SENAC, 2001.

MATA, M. C. De la cultura masiva a la cultura mediática. Diálogos de la comunicación, n. 56, Lima, 1999, p. 80-91. Disponível em <www.felafacs.org/dialogos>. Acesso em: 20 de março, 2009.

MONTESPERELLI, P. Sociología de la memoria. 1. ed. Buenos Aires: Nueva Visión, 2004.

OLIVEIRA, R. Identidades argentinas dinamizadas nas relações midiáticas $e$ comunicacionais de um grupo de imigrantes argentinos, residentes na cidade de Porto Alegre/RS. 2007. 273 f. Tese (Doutorado em Ciências da Comunicação). Universidade do Vale do Rio dos Sinos, São Leopoldo.

POLLAK, M. Memória, esquecimento, silêncio. Estudos históricos, n. 3, v. 2, Rio de Janeiro, 1989, p.3-15. Disponível em:

<http://www2.uel.br/cch/cdph/arqtxt/Memoria_esquecimento_silencio.pdf $>$. Acesso em: 10/06/2007. 
RICOEUR, P. La memoria, la historia, el olvido. Madrid: Trotta, 2003.

ROSSI, Paolo. El pasado, la memoria, el olvido. Buenos Aires: Nueva Vision, 2003.

SARLO, B. Tempo Passado: cultura da memória e guinada subjetiva. São Paulo: Companhia das Letras/Belo Horizonte/UFMG, 2007.

STROHSCHOEN, Ana Maria. Mídia e memórias coletivas. 2003. 211 f. Tese (Doutorado em Ciências da Comunicação). Unisinos, São Leopoldo.

TODOROV, T. Los abusos de la memoria. Barcelona: Paidós, 2000.

Memoria del mal, tentación del bien: indagaciones sobre el siglo XX. Barcelona: Península, 2002. 